\title{
Pterodontic Acid Isolated from Laggera pterodonta Inhibits Dengue Virus Serotype 2 Infection
}

\author{
Lin Qin ${ }^{1 \dagger}$, Wen $\mathrm{Li}^{1,2 \dagger}$, Lanchun Zhang ${ }^{1}$, Xinhua Wang ${ }^{3}$, Yutao Wang ${ }^{3}$, Haofei Yu ${ }^{1 *}$, Weiyan $\mathrm{Hu}^{1 *}$ and \\ Rongping Zhang ${ }^{1 *}$ \\ ${ }^{1}$ School of Pharmaceutical Science, China \\ ${ }^{2}$ Third Hospital of Yunnan Province, China \\ ${ }^{3}$ State Key Laboratory of Respiratory Disease, China \\ ${ }^{+}$These authors contributed equally to this work \\ *Corresponding author: Haofei Yu, School of Pharmaceutical Science, Yunnan Key Laboratory of Pharmacology for Natural \\ Products, Kunming 650000, China \\ Weiyan Hu, School of Pharmaceutical Science, Yunnan Key Laboratory of Pharmacology for Natural Products, Kunming 650000, \\ China \\ Rongping Zhang, School of Pharmaceutical Science, Yunnan Key Laboratory of Pharmacology for Natural Products, Kunming \\ 650000, China
}

\section{ARTICLE INFO}

Received: 幽 April 26, 2019

Published: May 10, 2019

Citation: Lin Qin, Wen L, Lanchun Zhang, Xinhua Wang, Yutao Wang, Haofei Y, Weiyan H, Rongping Zhang. Pterodontic Acid Isolated from Laggera pterodonta Inhibits Dengue Virus Serotype 2 Infection. Biomed J Sci \& Tech Res 17(5)-2019. BJSTR. MS.ID.003075.

Keywords: Laggera Pterodonta; Pterodontic Acid; Dengue Virus Serotype 2; Antiviral Activity; Sesquiterpenes
ABSTRACT

Dengue is the most important arbovirus disease in the world in terms of the highest morbidity and mortality. Unfortunately, there is no specific medication for it so far. In the present study, we investigated the anti-DENV-2 activity of Pterodontic acid, isolated from Laggera pterodonta. Pterodontic acid was found to have strong activity in vitro against DENV-2 with low cytotoxicity. These findings suggest that Pterodontic acid has the potential to be developed into an anti virus drug for the prevention and treatment of DENV-2 virus infection.

Abbreviations: CCL-5: Chemokine (C-C motif) Ligand 5; CPE: Cytopathic Effect; Denv-2 : Dengue Virus Serotype 2; DF: Dengue Fever; DHF: Dengue Hemorrhagic Fever; DHTMF: 3, 5-Dihydroxy-6, 7, 3'4'-tetramethoxyflavone; DSS: Dengue Shock Syndrome; HSV-I: Herpes Simplex Type I; HSV-II: Herpes Simplex Type II; L. Pterodonta: Laggera Pterodonta;

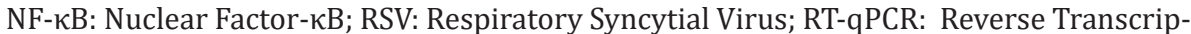
tion-Quantitative Polymerase Chain Reaction; TCM: Traditional Chinese Medicine; TFLP: Total Flavonoids of L. Pterodonta; TNF- $\alpha$ : Tumor Necrosis Factor Alpha; TPLP: Total Phenolics from L. Pterodonta

\section{Introduction}

The dengue virus (DENV) is transmitted between human beings and primarily Aedes aegypti mosquitoes [1]. Dengue virus (DENV) is endemic in tropical and sub-tropical regions of the world Bhatt et al. [2]. An estimated 390 million people are infected annually, of which 96 million cases are symptomatic but fewer than $1 \%$ of cases are fatal $[2,3,5]$. Most clinically apparent infections result in a selflimiting febrile illness called 'dengue fever'. However, a minority of patients develop dengue hemorrhagic fever-dengue shock syndrome, a more serious manifestation characterized by vascular leakage and circulatory failure [6]. There are four serotypes of DENV (DENV1-DENV4), which differ at the amino-acid level by $30-35 \%$ [6]. Infection with one serotype generates antibodies that may cross-react and enhance infection with other serotypes in a secondary infection [7]. No specific treatment exists for dengue fever, and vector control has been largely ineffective at preventing the rapid geographic spread of the disease [8-10]. Therefore, it is necessary to develop an innovative antiviral drug. 
Traditional Chinese medicine (TCM) is widely used in China to treat viral disease. TCM is considered to be safe, effective and multi-targeted [11]. Numerous medicinal plants exhibit antiviral activity through different mechanisms and these may lead to the development of novel antiviral drugs [11]. Laggera pterodonta (DC.) Benth. (Compositae) is a perennial herb widely distributed in southwest China, especially in Yunnan province [12]. Certain antiviral compounds have been isolated from L.pterodonta, including flavonoids, which have an anti-inflammatory and anti-apoptotic effect, in addition to three dicaffeoylquinic acids that display antiviral activity against herpes simplex virus-1, herpes simplex virus-2 and influenza A in vitro [11]. The sesquiterpene fraction of L. pterodonta had an anti-influenza virus effect. Pterodontic acid is one of the main sesquiterpenoids from L. pterodonta, which showed selective anti-viral activities to H1 subtype of human influenza A virus [12], its effect on DENV-2 has not been reported before. In this study, the antivirus activity of pterodontic acid is evaluated using cytopathic effect (CPE) reduction assay and RT-PCR.

\section{Materials and Methods}

\section{Plant Material and Preparation of Pterodontic Acid}

The whole herb of Laggera pterodonta, a traditional herbal medicine with the Chinese name Chou Ling Dan, was collected from Yunnan province of China. The herbarium specimen was authenticated by Professor Rongping Zhang and deposited in the College of Pharmaceutical Sciences, Kunming Medical University. The powdered plant material $(1 \mathrm{~kg}$ ) was extracted with methanol using a percolation process, followed by collecting a $40 \mathrm{~L}$ elution and vacuum-concentrating to yield a $135 \mathrm{~g}$ methanol extract. The extract was suspended in $\mathrm{H}_{2} \mathrm{O}(800 \mathrm{~mL})$ and subjected to liquidliquid partition by adding petroleum ether. The residue (48 $\mathrm{g}$ ) of the petroleum ether layer was subjected to silica gel CC (petroleum ether-EtOAc, 10:1) to obtain fraction A (38 g). Fraction A (8g) was subjected to silica gel CC with elution by a gradient of petroleum ether-EtOAc $(1: 0 ; 20: 1 ; 10: 1 ; 5: 1 ; 2: 1)$ to yield fractions $1-12$ based on TLC analysis. Fr.1 (3.8 g) was the petroleum ether elution and main elution of Fraction A. Fr.1 was further subjected to silica gel CC (petroleum ether-CHCl3, from 100:0 to 95:5) to obtain five fractions (I-V) for TLC analysis, Fr.III was further purified by gel CC to afford a compound (34.7 mg) with purity higher than $95 \%$, which was identified as pterodontic acid (Figure 1).

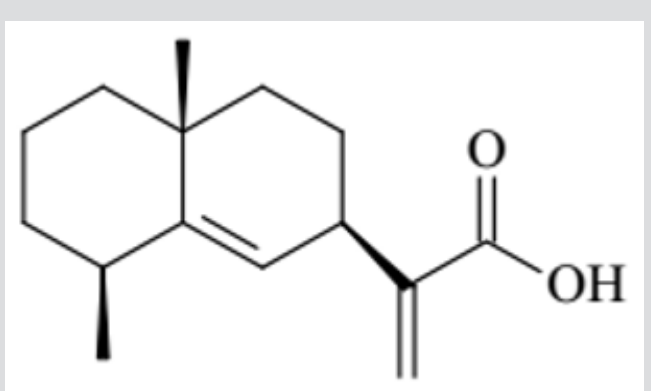

Figure 1: Chemical structure of pterodontic acid.

\section{Cells and Viruses}

C6/36 cells were grown in RPMI-1640 and MEM (1:2) with 10\% Fetal Bovine Serum (FBS) (Zhejiang Tianhang Biotechnology Co., Ltd), and penicillin/ streptomycin $(\mathrm{P} / \mathrm{S})$, at $28^{\circ} \mathrm{C} \pm 2^{\circ} \mathrm{C}$.

\section{Cytopathic Effect (CPE) Inhibition Assay}

C6/36 cells (200 $\mu \mathrm{l} /$ well) were seeded in 96-well plates and grown until cell monolayers were formed. The supernatant was removed and $3 \mu \mathrm{l}$ of DENV-2 was inoculated onto cell monolayer at 37

${ }^{\circ} \mathrm{C}$ for $2 \mathrm{~h}$. Infected cells were cultured in the presence of pterodontic acid $(5 \mu \mathrm{g} / \mathrm{ml})$ in maintenance medium. Each drug was tested in triplicate wells. After $72 \mathrm{~h}$ incubation at $37 \circ \mathrm{C}$ in a $5 \% \mathrm{CO}_{2}$ atmosphere, the cytopathic effect (CPE) was observed by microscopy.

\section{Reverse Transcription-Quantitative Polymerase Chain Reaction (RT-qPCR) Assay}

C6/36 cells (200 $\mu \mathrm{l}$ /well) were seeded in 96-well plates and grown until cell monolayers were formed. The supernatant was removed and $3 \mu \mathrm{l}$ of DENV-2 was inoculated onto cell monolayer at $37^{\circ} \mathrm{C}$ for $2 \mathrm{~h}$. Infected cells were cultured in the presence of pterodontic acid $(5 \mu \mathrm{g} / \mathrm{ml})$ in maintenance medium. Each drug was tested in triplicate wells. After $72 \mathrm{~h}$ incubation at $37{ }^{\circ} \mathrm{C}$ in a $5 \% \mathrm{CO}_{2}$ atmosphere, for the extraction of RNA from cell cultures, RNA was obtained from $140 \mu \mathrm{L}$ of supernatant. Viral RNA was extracted using an QIAamp® Viral RNA Mini Kit (Qiagen). Total RNA (7 $\mu$ l) was reverse transcribed into cDNA using the RevertAid First Strand cDNA Synthesis Kit (Fermentas). qPCR was performed with the following thermocycling conditions: $95^{\circ} \mathrm{C}$ for $3 \mathrm{~min}$, followed by 39 cycles of $95^{\circ} \mathrm{C}$ for $10 \mathrm{sec}, 55^{\circ} \mathrm{C}$ for $20 \mathrm{sec}$ and $72^{\circ} \mathrm{C}$ for $30 \mathrm{sec}$. The RT-qPCR primers: Forward primer, GCAGGGATACTGAAGAGATGGG; Reverse primer , TGGTTCTCCGTTACGTGTGG. The size of the RTPCR product was $186 \mathrm{bp}$.

\section{Statistical Analysis}

The statistical analysis was conducted using SPSS for Windows (version 15.0). In all cases, a probability of $\mathrm{p}<0.05$ in a two-tailed test was considered statistically significant.

\section{Results}

\section{The Pathological Changes of C6/36 Cells after DENV-2 Infection}

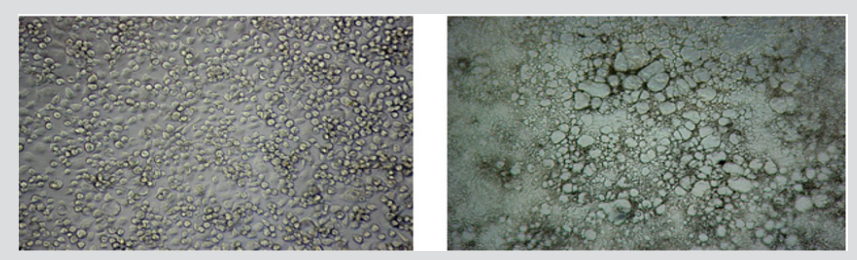

Figure 2: The pathological changes of $\mathrm{C} 6 / 36$ cells after DENV-2 infection.

C6/36 cells were seeded in 96-well plates, $3 \mu \mathrm{l}$ of DENV-2 was inoculated onto $\mathrm{C} 6 / 36$ cells, The pathological changes of $\mathrm{C} 6 / 36$ 
cells after DENV-2 infection was observed by microscopy (Figure 2). Changes of C6/36 cells after DENV-2 infection, normal C6/36 cells; 2. C6/36 cells after DENV-2 infection.

\section{Cytotoxicity of Pterodontic Acid}

Pterodontic acid was examined for its cytotoxic ability in confluent C6/36 cell cultures. No significant cytotoxic effects were observed at $5 \mu \mathrm{g} / \mathrm{ml}$ (Table 1). Cytopathogenic effect (CPE)

$$
\begin{aligned}
& \text { '-' : CPE 0\%; } \\
& \text { '+' : CPE 25\%; } \\
& \text { '++' : CPE50\%; } \\
& \text { '+++' : CPE75\%; } \\
& \text { '++++' : CPE } 100 \%
\end{aligned}
$$

Table 1: Cytotoxicity of Pterodontic acid in confluent C6/36 cell cultures without DENV-2.

\begin{tabular}{|c|c|c|c|}
\hline & \multicolumn{3}{|c|}{$\mathbf{7 2 h}$ (CPE) } \\
\hline pterodontic acid $(5 \mu \mathrm{g} / \mathrm{ml})$ & \pm & \pm & \pm \\
\hline acetone & - & - & - \\
\hline C6/36 & - & - & - \\
\hline
\end{tabular}

\section{Antiviral Activity of Pterodontic Acid}

To evaluate the antiviral activity of Pterodontic acid, C6/36 cells were infected with DENV-2 virus and Pterodontic acid was added at $5 \mu \mathrm{g} / \mathrm{ml}$. Following treatment for $72 \mathrm{~h}$, the antiviral effect of Pterodontic acid was evaluated. Cytopathogenic effect (CPE) of Pterodontic acid is $++(50 \%)$, CPE of oseltamivir is $++\sim+++(50 \% \sim 75 \%)$. Pterodontic acid exhibited an antiviral effect on DENV-2 (Table 2).

Table 2: Antiviral activity of Pterodontic acid (CPE).

\begin{tabular}{|c|c|c|c|}
\hline Medicine & \multicolumn{3}{|c|}{ 72h (CPE) } \\
\hline Pterodontic acid (5ug/ml) & ++ & ++ & ++ \\
\hline acetone & +++ & +++ & +++ \\
DENV-2 without medicine & & & \\
\hline C6/36 & +++ & +++ & +++ \\
\hline
\end{tabular}

\section{Inhibition of the mRNA of DENV-2}

The effects of Pterodontic acid on the mRNA of DENV-2 were determined. DENV-2 amplification inhibition rate $=(1-2$ $\triangle \mathrm{Ct}) \times 100 \%$. DENV-2 amplification inhibition rate in Pterodontic acid-treated cells after $72 \mathrm{~h}$ is $44.26 \%$. The results revealed that the DENV-2 mRNA was significantly reduced in Pterodontic acid-treated cells after $72 \mathrm{~h}$ (Table 3 ).

Table 3: DENV-2 amplification inhibition rate.

\begin{tabular}{|c|c|c|c|c|c|c|c|c|}
\hline \multirow{2}{*}{ Medicine } & time & \multicolumn{3}{|c|}{ Ct } & & & \\
\cline { 2 - 9 } & & $\mathbf{1}$ & $\mathbf{2}$ & $\mathbf{3}$ & mean Ct & $\triangle \mathbf{C t}$ & $\mathbf{2 -} \triangle \mathbf{C t}$ & $(\mathbf{1 - 2}-\triangle \mathbf{C t}) \times \mathbf{1 0 0} \%$ \\
\hline pterodontic acid & $72 \mathrm{~h}$ & 16.06 & 16.52 & 15.81 & 16.13 & 0.8433 & 0.5574 & 0.4426 \\
\hline acetone & $72 \mathrm{~h}$ & 16.95 & 17.33 & 17.27 & 17.183 & 0.1667 & 0.8909 & 0.1091 \\
\hline
\end{tabular}

\section{Discussion}

Each of the four serotypes of DENV (DENV-1, DENV-2, DENV-3, and DENV-4) is capable of causing the full spectrum of clinical manifestations following infection, including asymptomatic infection, dengue fever (DF), and the most severe disease, dengue hemorrhagic fever/dengue shock syndrome (DHF/DSS). No specific treatment exists for dengue fever, and vector control has been largely ineffective at preventing the rapid geographic spread of the disease Manokaran et al. [13]. Although there is a commercially available vaccine, its efficacy is poor and there are no alternative therapeutics Lim et al. [14]. In the present study, Pterodontic acid isolated from Laggera pterodonta was evaluated, no significant cytotoxic effects were observed at $5 \mu \mathrm{g} / \mathrm{ml}$. Pterodontic acid exhibited an antiviral effect on DENV-2. DENV-2 mRNA was significantly reduced in Pterodontic acid-treated cells after $72 \mathrm{~h}$. There are four serotypes of DENV, immunity to one serotype does not necessarily protect against infection with another serotype. Sequential infections are common in DENV-endemic countries, where all four serotypes often circulate at the same time or replace each other in a cyclical manner. Adverse clinical outcomes are more frequent during secondary or recurrent infections Culshaw et al. [6].

DENV-2 and DENV-4 appear to be less frequently associated with severe disease during primary infection than DENV-1 and
DENV-3. Host factors can contribute significantly to dengue disease severity. There is an increase in the incidence of DHF/DSS with increasing age. As the interval between primary and secondary infection increases, there appears to be an increase in the severity of secondary infection Murphy et al. [16].

Laggera pterodonta is widely distributed in the South-West of China, especially in Yunnan Province Gu et al. $[17,18]$. Numerous of chemical constituents such as eudesmane derivatives, sesquiterpenoid glucosides, flavones, steroids, coumarins, triterpenes as well as phenolic acids have been isolated mainly from the ethanol extract of L.pterodonta Shi et al. [19]. Previous work revealed that sesquiterpenes are the major components of the plant Gu et al. [17]. L.pterodonta is traditionally employed as ethnomedicine because of its anti-inflammatory, antibacterial activities and anti-leukemia activity Xiao et al. [18-20], its essential oil relieves cough, reduces sputum $\mathrm{Gu}$ et al. [6], it's effective and safe for children with acute bronchiolitis Shang et al. [21], it has been used for several centuries to ameliorate hepatitis in China Wu et al. [22]

\section{Active Fractions were Isolated from L. pterodonta}

Fr 14 was isolated from L.pterodonta, it had a wide spectrum of anti-influenza virus activity. Fr14 inhibited p38/MAPK and then inhibited NF-kB and COX-2 Wang et al. [23]. 3, 5-Dihydroxy-6, 7, 
3'4'-tetramethoxyflavone (DHTMF) is a polymethoxyflavone isolated from L.pterodonta. DHTMF demonstrated good antiproliferative activities against a number of cancer cell lines Cao et al. [24]. The anti-inflammatory effect of the total flavonoids of L.pterodonta (TFLP) was evaluated with various in vivo models of both acute and chronic inflammation. The anti-inflammatory mechanisms of TFLP are probably associated with the inhibition of prostaglandin formation, influence on the antioxidant systems and the suppression of LZM release Wu et al. [22]. The hepatoprotective effect of total phenolics from L.pterodonta (TPLP) against CCI4-, D-GalN-, TAA-, and t-BHP-induced injury was examined in primary cultured neonatal rat hepatocytes. TPLP inhibited the cellular leakage of two enzymes, hepatocyte ASAT and ALAT, caused by these chemicals and improved cell viability. Neutralizing reactive oxygen species by nonenzymatic mechanisms may be one of main mechanisms of TPLP against chemical-induced hepatocyte injury Wu et al. [22].

The petroleum ether extract of L.pterodonta showed significant inhibitory effects on lymphocyte transformation. Liu et al. [24]. Chrysosplenetin and penduletin, two o-methylated flavonols isolated from the leaves of L.pterodonta, were found to have strong activity in vitro against enterovirus 71 (EV71) with low cytotoxicity Zhu et al. [2]. C8 is an active component isolated from Laggera pterodonta. Two eudesmane-type sesquiterpene compounds were identified in C8: pterodontic acid and pterodondiol. C8 was demonstrated to have a broad-spectrum effect against different influenza viruses, including human and avian influenza viruses. C8 inhibited Toll-like receptor 7, myeloid differentiation primary response protein 88 and tumor necrosis factor (TNF) receptor associated factor 6 expression, in addition to p65 phosphorylation. C8 may inhibit p65/NF- $\kappa$ B nuclear translocation. Additionally, C8 prevented an increase in cytokine mRNA expression, including interleukin (IL)-1 $\beta$, IL-6, IL-8 and C-C motif chemokine 2 (MCP-1). Furthermore, the protein expression of IL-6, IL-8, TNF- $\alpha$, C-X-C motif chemokine 10, MCP-1 and C-C motif chemokine 5 was inhibited Wang et al. [20].

Most sesquiterpenoids of L. pterodonta have an eudesmane skeleton and possess wide range of pharmacological activities. For instance, pterodontriol A, pterodontic acid, and ilicic acid have inhibitory effect on tumor cells. Pterodontic acid has an antiinflammatory effect as observed by decreasing xylene induced ear edema in mice. In vitro antiviral activity of pterodontic acid is most probably associated with inhibiting the replication of influenza A virus by blocking nuclear export of viral RNP complexes and attenuating the inflammatory response by inhibiting activation of the NF- $\kappa$ B pathway. Pterodontic acid might be a potential antiviral agent against influenza A virus. This implied that anti-viral activity of pterodontic acid was associated with reducing the release of both pro-inflammatory cytokines and chemokines. Therefore, pterodontic acid might be a potential lead compound for new antiDENV-2 drug development Guan et al. [11]. This study showed that pterodontic acid, one of the major sesquiterpenoids of L. pterodonta, had powerful in vitro activities of anti-DENV-2 virus. The result provide clues for developing a novel antiviral drug, further study is required to verify the mechanism.

\section{Acknowledgment}

This work was supported by the National Natural Science Foundation of China (No. U1502226, 81460593), National Key Technology R\&D Program (2014BAI01B01).

\section{Availability of Data and Materials}

The datasets used and/or analyzed during the current study are available from the corresponding author on reasonable request.

\section{References}

1. Saez Lloren X, Tricou V, Yu D, Rivera L, Jimeno J, et al. (2018) Immunogenicity and safety of one versus two doses of tetravalent dengue vaccine in healthy children aged 2-17 years in Asia and Latin America: 18-month interim data from a phase 2, randomised, placebocontrolled study. Lancet Infect Dis 18(2): 162-170.

2. Bhatt S, Gething PW, Brady OJ, Messina JP, Farlow AW, et al. (2013) The global distribution and burden of dengue. Nature 496(7446): 504-507.

3. Bhatia R, Dash AP, Sunyoto T (2013) Changing epidemiology of dengue in South-East Asia. WHO South East Asia J Public Health 2(1): 23-27.

4. Sabchareon A, Wallace D, Sirivichayakul C, Limkittikul K, Chanthavanich P, et al. (2012) Protective efficacy of the recombinant, live-attenuated, CYD tetravalent dengue vaccine in Thai schoolchildren: a randomised, controlled phase $2 \mathrm{~b}$ trial. Lancet 380(9853): 1559-1567.

5. Culshaw A, Ladell K, Gras S, Mc Laren JE, Miners KL, et al. (2017) Germline bias dictates cross-serotype reactivity in a common denguevirus-specific CD8(+) T cell response. Nat Immunol 18(11): 1228-1237.

6. Fibriansah G, Ibarra KD, Ng TS, Smith SA, Tan JL, et al. (2015) DENGUE VIRUS. Cryo-EM structure of an antibody that neutralizes dengue virus type 2 by locking E protein dimers. Science 349(6243): 88-91.

7. Guzman MG, Kouri G (2002) Dengue: an update. Lancet Infect Dis 2(1): 33-42.

8. Huy R, Buchy P, Conan A, Ngan C, Ong S, et al. (2010) National dengue surveillance in Cambodia 1980-2008: epidemiological and virological trends and the impact of vector control. Bull World Health Organ 88(9): 650-657.

9. Wilder Smith A, Gubler DJ, Weaver SC, Monath TP, Heymann DL, et al. (2017) Epidemic arboviral diseases: priorities for research and public health. Lancet Infect Dis 17(3): e101-e106.

10. Wang Y, Li J, Yan W, Chen Q Jiang Z, et al. (2018) An active component containing pterodontic acid and pterodondiol isolated from Laggera pterodonta inhibits influenza A virus infection through the TLR7/ MyD88/TRAF6/NFkappaB signaling pathway. Mol Med Rep 18(1): 523531.

11. Guan W, Li J, Chen Q Jiang Z, Zhang R, et al. (2017) Pterodontic Acid Isolated from Laggera pterodonta Inhibits Viral Replication and Inflammation Induced by Influenza A Virus. Molecules 22(10).

12. Manokaran G, Finol E, Wang C, Gunaratne J, Bahl J, et al. (2015) Dengue subgenomic RNA binds TRIM25 to inhibit interferon expression for epidemiological fitness. Science 350(6257): 217-221.

13. Lim XX, Chandramohan A, Lim XY, Bag N, Sharma KK, et al. (2017) Conformational changes in intact dengue virus reveal serotype-specific expansion. Nat Commun 8: 14339.

14. Murphy BR, Whitehead SS (2011) Immune response to dengue virus and prospects for a vaccine. Annu Rev Immunol 29: 587-619. 
15. Gu JL, Li ZJ, Zhang HX, Du ZZ (2014) Fragrant volatile sesquiterpenoids isolated from the essential oil of Laggera pterodonta by using olfactoryguided fractionation. Chem Biodivers, 11(9): 1398-1405.

16. Xiao Y, Zheng Q, Zhang Q, Sun H, Gueritte F, et al. (2003) Eudesmane derivatives from Laggera pterodonta. Fitoterapia, 74(5): 459-463.

17. Shi S, Huang K, Zhang Y, Zhao Y, Du Q (2007) Purification and identification of antiviral components from Laggera pterodonta by highspeed counter-current chromatography. J Chromatogr B Analyt Technol Biomed Life Sci 859(1): 119-124.

18. Shang X, Liabsuetrakul T, Sangsupawanich P, Xia X, He P, et al. (2017) Efficacy and safety of Laggera pterodonta in children 3-24 months with acute bronchiolitis: a randomized controlled trial. Clin Respir J 11(3): 296-304.

19. Wu Y, Yang L, Wang F, Wu X, Zhou C, et al. (2007) Hepatoprotective and antioxidative effects of total phenolics from Laggera pterodonta on chemical-induced injury in primary cultured neonatal rat hepatocytes. Food Chem Toxicol 45(8): 1349-1355.

\section{ISSN: 2574-1241}

DOI: 10.26717/BJSTR.2019.17.003075

Haofei Y, Weiyan H, Rongping Z. Biomed J Sci \& Tech Res

(C) This work is licensed under Creative

Submission Link: https://biomedres.us/submit-manuscript.php
20. Wang Y, Zhou B, Lu J, Chen Q Ti H, et al. (2017) Inhibition of influenza virus via a sesquiterpene fraction isolated from Laggera pterodonta by targeting the NF-kappaB and p38 pathways. BMC Complement Altern Med 17(1): 25.

21. Cao C, Liu B, Zeng C, Lu Y, Chen S, et al. (2014) A polymethoxyflavone from Laggera pterodonta induces apoptosis in imatinib-resistant K562R cells via activation of the intrinsic apoptosis pathway. Cancer Cell Int, 14(1): 137 .

22. Wu Y, Zhou C, Li X, Song L, Wu X, et al. (2006) Evaluation of antiinflammatory activity of the total flavonoids of Laggera pterodonta on acute and chronic inflammation models. Phytother Res 20(7): 585590 .

23. Liu YB, Jia W, Yao Z, Pan Q, Takaishi Y, et al. (2007) Two eudesmane sesquiterpenes from Laggera pterodonta. J Asian Nat Prod Res 9(3-5): 233-237.

24.Zhu QC, Wang Y, Liu YP, Zhang RQ, Li X, et al. (2011) Inhibition of enterovirus 71 replication by chrysosplenetin and penduletin. Eur J Pharm Sci 44(3): 392-398.

$\begin{array}{ll}\text { BIOMEDICAL } & \text { Assets of Publishing with us } \\ \text { RESEARCHES } & \text { - Global archiving of articles } \\ & \text { - Immediate, unrestricted online access } \\ & \text { - Rigorous Peer Review Process } \\ \end{array}$

